\title{
A model to explain the Mn enrichment in the rim of zoned garnet
}

\author{
Shohei BanNo ${ }^{1}$ and SABURo $\mathrm{CHII}^{2}$ \\ Department of Earth Sciences, Kanazawa University, Kanazawa $920^{1}$ \\ and Geological Institute, University of Tokyo, Hongo, Tokyo $113^{2}$, Japan
}

(Received May 24, 1978; accepted in revised form September 20, 1978)

\begin{abstract}
Zonal structure of garnet grown in metamorphism maintaining surface equilibrium was examined on the model system $\mathrm{Mn}_{3} \mathrm{Al}_{2} \mathrm{Si}_{3} \mathrm{O}_{12}-\mathrm{Fe}_{3} \mathrm{Al}_{2} \mathrm{Si}_{3} \mathrm{O}_{12} \cdot \mathrm{H}_{2} \mathrm{O}$. The model assumes that the diffusion of $\mathrm{Mn}$ and $\mathrm{Fe}$ in both garnet and chlorite is limited, or it is practically negligible in garnet. It is shown that if the rate of temperature change during metamorphism is large in comparison with diffusion rate, a zonal structure, in which the $\mathrm{MnO}$ content of garnet decreases from the center of the crystal towards rim and increases again at the rim, giving rise to the minimum $\mathrm{MnO}$ content at an intermediate zone, can be formed without accompanying resorption. Two natural examples which support the conclusion on the model system are discussed.
\end{abstract}

\section{INTRODUCTION}

Garnets in metamorphic rocks are commonly zoned in regard to $\mathrm{Mn}$. In most frequently observed pattern of the zonal structure, the core is enriched in $\mathrm{Mn}$ as compared with the rim. From the view points of surface equilibrium between the outer surface of garnet and coexisting phases, this type of the Mn distribution can be explained as the results of changing physical conditions of metamorphism, usually by progressive metamorphism (MUELLER and SCHNEIDER, 1971; BANNO and KURATA, 1972; KRETZ, 1973).

With the accumulation of data, it became apparent that another type of zonal structure, in which the Mn content of garnet increases towards its rim, is not uncommon in metamorphic rocks. In this paper, the zonal structure of garnet with Mn-rich core and Mn-poor rim will be called normal and that with Mn-poor core and Mn-rich rim will be called reverse for brevity. A type of zoning, in which the Mn content is high in the core, decreases towards the rim, and increases again in the rim, giving rise to the appearance of minimum $\mathrm{Mn}$ content in an intermediate zone, will be called the mixed-type zoning. Genesis of reverse and mixed zonings has been interpreted in terms of polymetamorphism (EDMUNDS and ATHERTON, 1971; KANO and KURODA, 1973), non-equilibrium cryatallization (KRETZ, 1973) and resorption or retrograde metamorphism (GRAND and WeIBLEN, 1971; DE BÉTHUNE et al., 1975).
DE BÉTHUNE et al. (1975) have presented clear evidences to support the last idea, and undoubtedly many of the reverse-zoned garnets can be explained by their model. However, there have been described reverse-zoned garnets without clear textural evidences of resorption.

In the following, we intend to present a model which is capable to explain the reversezoned garnet without taking into account the resorption.

\section{ModeL}

Let us discuss the genesis of garnet zoning in the system $\mathrm{Mn}_{3} \mathrm{Al}_{2} \mathrm{Si}_{3} \mathrm{O}_{12}-\mathrm{Fe}_{3} \mathrm{Al}_{2} \mathrm{Si}_{3} \mathrm{O}_{12}$ with excess $\mathrm{H}_{2} \mathrm{O}$ and $\mathrm{SiO}_{2}$. We assume complete solid solution between the $\mathrm{Mn}$ and $\mathrm{Fe}$ end members, and hydrospessartine is ignored. Thus in this idealized model system, garnet and chlorite are related by the following chemical reactions:

$$
\begin{aligned}
& \text { chlorite }+ \text { quartz }=\text { garnet }+ \text { water } \\
& 2 \mathrm{Mn}_{4.5} \mathrm{Al}_{3} \mathrm{Si}_{2.5} \mathrm{O}_{10}(\mathrm{OH})_{8}+4 \mathrm{SiO}_{2} \\
& =3 \mathrm{Mn}_{3} \mathrm{Al}_{2} \mathrm{Si}_{3} \mathrm{O}_{12}+4 \mathrm{H}_{2} \mathrm{O} \\
& 2 \mathrm{Fe}_{4.5} \mathrm{Al}_{3} \mathrm{Si}_{2.5} \mathrm{O}_{10}(\mathrm{OH})_{8}+4 \mathrm{SiO}_{2} \\
& =3 \mathrm{Fe}_{3} \mathrm{Al}_{2} \mathrm{Si}_{3} \mathrm{O}_{12}+4 \mathrm{H}_{2} \mathrm{O}
\end{aligned}
$$

This model system is the same as that of KRETZ (1973) who discussed the relationships 
between the zoning patterns, and the constraints on equilibrium and material transfer of the system. We assume that local equilibrium is maintained throughout the system, and the diffusion of cations in garnet and chlorite is limited, but it is much faster in the latter than in the former. This model is somewhat similar to model " $\mathrm{d}$ " of KRETZ, but we assume that local equilibrium is always maintained in regard to both of $\mathrm{Mn}$ and $\mathrm{Fe}$. We also assume that the rate of garnet growth is essentially diffusion controlled. Therefore, in the model system of this paper, the compositions of garnet and chlorite at their surfaces are uniquely determined by temperature, if isobaric and water saturated metamorphic reactions are being considered.

Figure 1 is a schematic phase diagram of the model system. One may give more quantitative expressions to the model by applying the experiments of Hsu (1968), but it is not essential here. Let us see below what kind of zonal structure is formed in garnet of the model system by metamorphism.

For the bulk composition B let us increase the temperature until $T_{4}$, the maximum temperature of metamorphism, is reached. At $T_{1}$, incipient garnet with composition $\mathrm{G}_{1}$ coexists with homogeneous chlorite with $\mathrm{C}_{1}$. At $T_{2}$, garnet with $G_{2}$ coexists with chlorite $C_{2}$, but

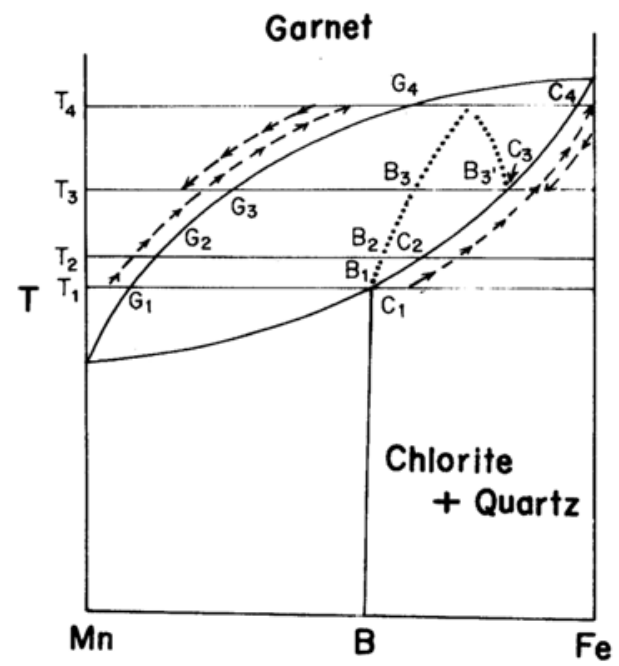

Fig. 1. Schematic phase diagram of binary $\mathrm{Mn}_{3} \mathrm{Al}_{2} \mathrm{Si}_{3}$ $\mathrm{O}_{12}-\mathrm{Fe}_{3} \mathrm{Al}_{2} \mathrm{Si}_{3} \mathrm{O}_{12}$ with excess $\mathrm{H}_{2} \mathrm{O} . G_{1}, \mathrm{C}_{1}, G_{2}, \mathrm{C}_{2}$ etc. are the compositions at the surfaces of garnet and chlorite at temperatures $T_{1}, T_{2}$ etc. $B$ is the effective bulk composition, i.e., the bulk composition involved in chemical reaction or the bulk composition minus the amount frozen inside garnet, which is not involved in reaction. garnet, to which we assume very slow diffusion, is zoned with the core of $G_{1}$ and rim of $G_{2}$. Chlorite is also zoned with $\mathrm{C}_{2}$ in the rim, but its core may not have $\mathrm{C}_{1}$ as we assume the diffusion to be more effective in chlorite than in garnet. Then the core should have composition between $C_{1}$ and $C_{2}$. The composition of chlorite depends on the diffusion coefficients of $\mathrm{Mn}^{2+}$ and $\mathrm{Fe}^{2+}$, rate of temperature change $\mathrm{d} T / \mathrm{d} t$ ( $t$ : time) and the size of minerals, and cannot be estimated from the phase diagram alone. With the further increase of temperature, the compositions change to $\mathrm{G}_{4}$ and $\mathrm{C}_{4}$, respectively, at the maximum temperature $T_{4}$. In equilibrium crystallization, chlorite disappears at a certain temperature between $T_{3}$ and $T_{4}$. If the system is kept at $T_{4}$ sufficiently long to homogenize and consume chlorite, we have broad and homogeneous rim of garnet. If, on the other hand, temperature starts to decrease before chlorite is homogenized, garnet continues to grow, but this time adding successively Mnricher rim as temperature decreases. With the decrease of temperature, the rims of garnet and chlorite tend to be Mn-richer and then the compositional gradient in chlorite is reduced and at certain temperature, say, $T_{3}$, it is homogenized. With the further decrease of temperature chlorite is now undersaturated with the Mn-end member and does not decompose, but garnet, being over-

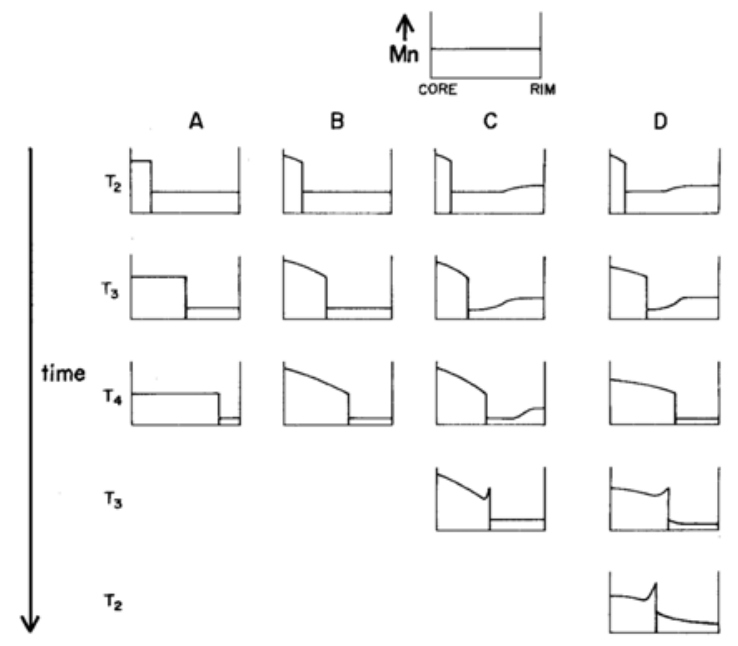

Fig. 2. Schematic representation of zoning pattern of garnet in the model binary and one dimensional system. A: complete equilibrium, $B:$ no diffusion in garnet and complete diffusion in chlorite, $C$ : no diffusion in garnet and limited diffusion in chlorite, D: limited diffusion both in garnet and chlorite, but diffusion is much easier in the latter. 
saturated with the almandine component at the rim, begins to be resorbed if there is sufficient water for hydration reaction. Or, if water is not available, no more reaction takes place and mix-zoned garnet and homogeneous chlorite remain in the system upon further cooling. Figure 2 shows the variation of the garnet and chlorite compositions in the process mentioned above for the one dimensional model, in which the nucleation of garnet does not take place in metastable chlorite.

Which of two alternative processes proceeds below $T_{3}$, depends on the behavior of water during metamorphism. Generally, mineral assemblages at high temperatures of metamorphism are preserved well and this phenomenon is interpreted by the difficulty of water supply for the dehydration reaction (MIYASHIRO, 1965). In our model, we assume excess $\mathrm{H}_{2} \mathrm{O}$ to simplify the thermodynamics of the system, but in actual metamorphic rocks the space for pore solution is so small that the rocks cannot store all the water liberated by the dehydration reaction of progressive metamorphism. The water released by the dehydration reactions then moves away to the outside of the system, probably to a higher level of the earth's crust. This is an irreversible process, since the easiness is not the same for water release from and water supply to the rocks being metamorphosed. The water supply needs work done against the gravity. Therefore, metamorphic reactions ceases at $T_{3}$ or at slightly lower temperature unless some special processes operate to supply the water of hydration reaction. Figure 2 compares the zoning patterns of garnet and chlorite of the model system corresponding to various assumptions discussed in the text.

The model discussed above can be improved by introducing limited diffusion in garnet to result in the Mn enrichment by inward Mn diffusion due to resorption, but it is out of the scope of the present paper.

The types of garnet zoning obtained by the process given above are dependent on the balance of several factors, the diffusion coefficient, rate of temperature change, the size of minerals and so on, and mixed-type zoning shown in Fig. 2 is formed only for certain combination of these factors. If the rate of temperature change is low, the diffusion in chlorite is sufficiently fast and we obtain normally zoned garnet. It is essential that $\mathrm{d} T / \mathrm{d} t$ is steep and metastable chlorite persists until the maximum temperature is reached to form reverse and mixed-type zonings.

In the foregoing discussions, we have assumed that garnet is formed by the reactions to consume chlorite. If strictly interpreted, this model applies only to the garnet formation in high pressure and low temperature metamorphism and does not apply to those in medium and low pressure metamorphism, in which garnet is formed at the expense of biotite, chlorite and cordierite. The reactions to form garnet from biotite-bearing assemblages are more complicated than eqs. (1) and (2), but so far as ferro-magnesian sheet silicates are the major source of garnet-forming materials, there are essential similarities among the reactions to consume sheet silicates. Therefore, the discussion given above can be extended to the reactions consuming biotite as well.

\section{Geological ImPlications}

The model presented above can explain in theory the genesis of reverse and mixed-zoned garnets, but we know little of the magnitude of the parameters involved, and hence the validity of the model in natural process has to be sought in natural metamorphic rocks.

Our model predicts the presence of compositional gradient in layered silicates during the garnet growth and Mn-enrichment at the rim of garnets, which are free from resorption. Petrography of a few metamorphic rocks wili be reviewed to examine the predictions.

Compositional gradient in sheet silicates If garnet forming reactions in the model system proceeds ideally, and hydration reaction does not take place, we have zoned garnet and homogeneous chlorite with composition $\mathrm{C}_{3}$. If the reaction is incomplete, however, we have zoned garnet and zoned chlorite, with $\mathrm{Mn}$ richer in the core than in the rim. Thus, the chemical heterogeneity of chlorite, or biotite, may offer evidences to support or discredit the model we have discussed. Zoned chlorite with $\mathrm{Mn}$ - and $\mathrm{Fe}$ - rich rim and $\mathrm{Mg}$ - rich core has been described from Sanbagawa schists by KuRATA (1972), who attributed its genesis to the hydration of garnet. Chlorite or biotite associated with garnet, however, is usually homogeneous, as is shown by Hollister (1966). In natural metamorphic rocks, however, we may replace the role played by the zoned chlorite by the concentration gradient among chlorites or biotites dispersed in the matrix. A good example 
of such a compositional gradient was described on biotite in a garnet-biotite schist of staurolitegrade described by KWAK (1970) from the Sudbury region. He has shown in his Fig. 8 that biotites in a zone about $0.5 \mathrm{~mm}$ wide around a garnet-rich portion of the specimen has such a compositional gradient that $\mathrm{MnO}$ content decreases towards garnet by a factor of $2 / 3$, and the $\mathrm{MgO}$ content increases, even though the heterogeneity of individual grains has not been described. The garnets in that specimen have Mnrich rim, but they have irregular outline which may be of resorption origin. The compositional gradient among biotites cannot be explained by the resorption of garnet, as it should give reversed type concentration gradient as the chlorite of the Sanbagawa schists, so it is possible that the reverse-zoned garnet and the compositional gradient among biotites were due to the garnet growth with falling temperature, even though the Mn-enrichment at the garnet rim could have been enhanced by resorption.

Reverse-zoned garnet in a Ryoke hornfels ONO (1975 a, b) has described zoned garnets in pelitic hornfelses of the Ryoke metamorphic belt. He has shown on a pelitic hornfels of the Ohkubo area (ONO, 1975 b) that some of the zoned garnets are euhedral and have flat crystal surfaces with growth hills on them, while there are garnets with curved surfaces. The zoning with $\mathrm{MnO}$-poor $(\mathrm{MnO}=11.5$ wt. $\%)$ core and $\mathrm{MnO}$ rich rim $(\mathrm{MnO}=18.5 \mathrm{wt}$. \%) is ubiquitous, except for a few irregularly shaped crystals, regardless of the size of garnets, so ONO concluded that all the garnet grains experienced similar thermal history. The garnets with flat surfaces are also zoned in the same manner.

Resorption model cannot be applied to the euhedral garnets with flat growth surfaces. If the zoning was formed by the reequilibration of $\mathrm{Mn}-\mathrm{Fe}$ partitioning between garnet and biotite resulted from falling temperature, the width of the Mn-rich rim may be similar for all the grains, thereby giving rise to the difference of $\mathrm{MnO}$ content in the core of fine-grained and coarsegrained garnets. Therefore, it seems that the zoning was formed during crystal growth. As the compositional gradient in biotite was not detected, the genesis of the zoned garnets in the hornfels cannot equivocally attributed to the growth model discussed in this paper, but the model presents the most plausible explanation we could think of.

\section{CONCLUding Remarks}

Based on the surface equilibrium model, we have presented a model of garnet-chlorite (or biotite) equilibrium which can give rise to the formation of garnet zoning, in which $\mathrm{MnO}$ content decreases from the core towards the rim, but again increases at the edge of the crystal. The same zoning pattern is undoubtedly formed where once normally zoned garnet is resorbed, when the temperature of metamorphism decreases from its maximum, but there are a few examples of the zoned garnets which are more easily explained by our model than the resorption one. As our model is based on incomplete diffusion in sheet silicates, it fits better to the garnet growth with steep $\mathrm{d} T / \mathrm{d} t$, i.e., it may be more appropriate to the garnet zoning in contact aureole than in regional metamorphic terrains.

Acknowledgements-We thank Mr. K. NAKAMURA for drafting figures and Mrs. Y. FUKUDA for typewriting the manuscript.

\section{REFERENCES}

BANNO, S. and Kurata, H. (1972) Distribution of $\mathrm{Ca}$ in zoned garnet of low-grade pelitic schists. $J$. Geol. Soc. Japan. 78, 507-512.

EDMunds, W. M. and ATHERTon, M. P. (1971) Polymetamorphic evolution of garnet in Fanad aureole, Donegal, Eire. Lithos 4, 147-161.

De Bethune, P., Laduron, D. and Boceuet, J. (1975) Diffusion processes in resorbed garnet. Contr. Mineral. Petrol. 50, 197-204.

Grant, J. A. and WeIblen, P. W. (1971) Retrograde zoning in garnet near the second sillimanite isograde. Am. J. Sci. 270, 281-296.

HOLLISTER, L. S. (1966) Garnet zoning: an interpretation based on the Rayleigh-fractionation model. Science 154, 1647-1651.

HsU, L. C. (1968) Selected phase relationships in the system Al-Mn-Fe-Si-O; a model system for garnet equilibria. J. Petrol. 9, 40-83.

KANO, H. and KURODA, Y. (1973) On the chemistry on coexisting garnet and biotite in pelitic-psammitic metamorphic rocks, central Abukuma, Japan. $J$. Geol. Soc. Japan 79, 621-641.

KRETZ, R. (1973) Kinetics of the crystallization of garnet at two localities near Yellowknife. Canad. Mineral. 12, 1-20.

KuRATA, H. (1972) Local chemical heterogeneity of chlorites in Sanbagawa schists from Sazare area, central Shikoku. J. Geol. Soc. Japan 78, 653-657. 
KWAK, T. A. P. (1970) An attempt to correlate nonpredicted variations of distribution coefficients with mineral grain internal inhomogeneity using a field example studied near Sudbury, Ontario. Contr. Mineral. Petrol. 26, 199-224.

MIYASHIRO, A. (1965) Metamorphic rocks and metamorphic belts. Iwanami Syoten, Tokyo, i.e. 458 pp.

MUELlER, G. and SCHNEIDER, A. (1971) Chemistry and genesis of garnets in metamorphic rocks. Contr.
Mineral. Petrol. 31, 178-200.

ONO, A. (1975a) Spatial distribution, size and chemistry of garnet in a hornfels from the Takato area, Ryoke metamorphic belt, central Japan. J. Japan. Ass. Min. Petr. Econ. Min. 70, 169-173.

ONO, A. (1975b) Compositions and sizes of garnet crystals from a hornfels, Tenryukyo region of central Japan. J. Japan. Assoc. Min. Petr. Econ. Geol. 70, 194-199. 